\title{
A HYBRID SOLAR-WIND ENERGY GENERATION APPROACH FOR SRI LANKA
}

\author{
MENDIS, K.S.L. ${ }^{1}$, WAIDYASEKARA, K.G.A.S. ${ }^{2}$ \& GINTHOTAVIDANA, S.S.C. ${ }^{3}$ \\ 1,2,3 Department of Building Economics, University of Moratuwa, Colombo, Sri Lanka \\ ${ }^{1}$ slankadari@gmail.com, ${ }^{2}$ anuradha@uom.lk, ${ }^{3}$ sscgvidana@gmail.com
}

\begin{abstract}
The escalation of global energy demand has enhanced the interest on renewable energy technologies worldwide. The reliance of a single energy source has become problematic, and hybrid renewable energy technology has been identified as a feasible solution. Producing energy to limitless increasing demand is a challenging issue faced by Sri Lanka nowadays. Although, there are some studies carried out for renewable energy systems, solar-wind based hybrid renewable systems is an understudied area in Sri Lankan context. Hence, this paper aims to explore the applicability of hybrid solar-wind renewable energy generation approach for Sri Lanka. The study follows a qualitative approach with semi structured interviews from eight industrial experts, and manual content analysis technique was used for data analysis. The paper discussed the current installation practices of solar and wind technologies, applicability of hybrid solar and wind renewable energy systems and national level contribution for hybrid systems. Finally, a validated model was proposed to implement hybrid renewable energy generation systems for Sri Lanka.
\end{abstract}

Keywords: Energy Technologies; Renewable Energy; Hybrid Renewable Energy Technologies; Solar Energy; Wind Energy

\section{Introduction}

The worldwide energy consumption will escalate from $579 \mathrm{EJ}$ (Exajoules) in 2012 to $860 \mathrm{EJ}$ in 2040, causing $48 \%$ increase, and in the last two decades, a considerable increase in energy consumption of developing countries have been observed due to economic growth and growth of population (Scheffran, et al., 2020).As per the findings of Li, et al.(2014), buildings account for $40 \%, 39 \%$ and $37 \%$ of total energy consumption in the US, the UK and the European Union respectively. Further, Sri Lanka Sustainable Energy Authority (SLSEA) reveals that the largest energy consuming sector was the household and Industrial sector, accounting for $69.6 \%$ of the total energy demand of the country (SLSEA, 2018). It is a known fact that neighbouring India strives to ensure universal access to clean electricity to its population by 2030 (Sawhney, 2021). However, among South Asian nations such as Bangladesh, India and Pakistan, Sri Lanka has been recognized as the only nation who predominantly relies on renewable sources to supply its national energy output (Murshed, et al., 2020). Wijayatunga (2014) elaborated that along with the rapid development, small hydropower sector needs to facilitate expansion into other renewable energy sources in Sri Lanka. This headed the government to address these characteristics in the energy policy precisely because, producing energy to limitless increasing demand is a challenging issue faced by the country nowadays.

Bandara, et al. (2020), postulates that Sri Lanka is a tropical country with a plethora of renewable energy sources and penetration of them into the electrical grid can minimize the Cost of Energy and greenhouse gas emissions. The energy generation mix of Sri Lanka comprises of $49 \%$ thermal and $51 \%$ renewable energy, including $40.5 \%$ conventional hydropower (Kolhe, et al., 2015). A study by Umayangani (2019) has proven the possibility of fulfilling the total hourly energy demand of Sri Lanka using Solar, Wind and Hydro energy sources. However, the author emphasizes that the variability of the said energy sources throughout the year, has hindered the ability of using them exclusively to fulfill the hourly energy demand. On the other hand, Sri Lanka has not yet fully involved in upgrading its capabilities to enable 
maximum utilization of abundant clean energy sources such as solar and wind. Even though there are some studies carried out for hybrid renewable energy systems across the world, only a handful of research are targeted at proposing a hybrid energy system for Sri Lanka. Kolhe, et al. (2015) carried out a feasibility study for a an off-grid hybrid renewable energy system for supplying electricity to a rural community in the Siyambalanduwa region of Sri Lanka. Juserius and Ström (2021) evaluated the efficiency of a wind and solar hybrid system for a Sri Lankan household. Many studies have investigated the hybrid renewable energy concept (Wang, Palazoglu, and El-Farra, 2015), however limited studies are available on the application of the hybrid concept in Sri Lanka. In order to assist the investment decisions by stakeholders and policy makers, it is essential to conduct a comprehensive and independent analysis on hybrid renewable energy systems. Therefore, the main aim of this research is to explore the applicability of hybrid solar-wind renewable energy generation approach for Sri Lanka.

\section{Literature Review}

Fossil fuels such as coal, gas, and crude oil, contribute approximately about $80 \%$ to the total energy utilization (Alrikabi, 2014). In accordance with the discoveries of World Energy Outlook by International Energy Agency (2015), global energy requirement will raise by approximately one-third as at 2013 by 2040 and energy-associated $\mathrm{CO}_{2}$ emissions will have an anticipated rise by $16 \%$.

\subsection{UTILIZATION OF ENERGY ACROSS MULTIPLE SECTORS}

World energy utilization can be categorized under the energy consumption distributed to end users, while observing the sectorial consumption trends and patterns. International Energy Agency (IEA) represents the energy demand of each sector as illustrated in Figure 1. As depicted in Figure 1, among energy demands of all the sectors, industry sector is predicted to consume the highest amount of energy amounting to $42 \%$. According to International Energy Outlook (2016), the industrial sector accounts to and is forecasted to represent more than half of total distributed energy in the world by 2040. Residential is the second most energy consuming sector accounting to $26.9 \%$ of the total distributed energy consumed worldwide (International Energy Agency, 2020).

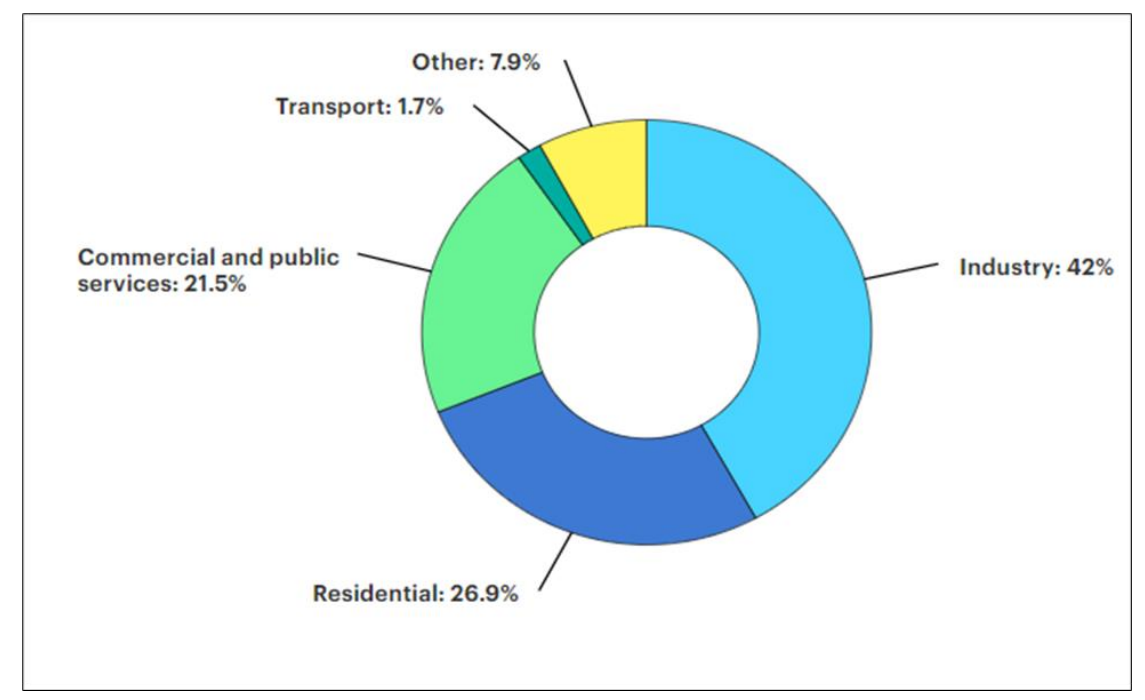

Figure 1, Energy demand by sector (Source: International Energy Agency, 2020)

\subsection{RENEWABLE ENERGY SOURCES}

Renewable energy sources have become world's fastest emerging energy source over the last few decades while the consumption of renewable energy is predicted to increase by an average of $2.6 \%$ between years 2012 to 2014 which would be 4 quadrillion Btu (British Thermal Units) by 2040 (International Energy Outlook, 2016). When providing clean, safe, and reliable power, solar energy is the most potential power source available which can be grouped in to two types as passive solar power and active solar power (Alrikabi, 2014). Active solar energy uses air or liquid to capture the heat while passive solar energy relies on thermodynamics to collect solar heat without any external devices. Kinetic energy of wind is converted into other forms of energy such as electricity through turbines in wind power systems (Daim, Harell and Hogaboam, 2012). There are forest product residues grown specifically for energy production where biomass power plants generate electricity from biomass resources ranging from agriculture (Renewables, 
2015). Hydroelectricity is the process which generates electricity by gravity fall or running water through driving a turbine and generator where the water storing dams are used as power source (Jacobson and Delucchi, 2011). Dry steam, hot water, hot dry rock, magma, and ambient ground heat are the geothermal power resources whereas geothermal heat pumps and ambient ground heat is used for commercial power (Bull, 2001). The cheapest method of generating electricity is drawing tidal power using the forceoscillating water columns of waves entering into a fixed device (Alrikabi, 2014). The rapid growth in renewables is strengthened by the expected rate of cost reductions of utility-scale solar PV and onshore wind to drop by around $25 \%$ and $40 \%$ over the next two decades (Energy Outlook, 2016). It is predicted that in $2050,90 \%$ of total electricity needs would be supplied through renewables followed by $6 \%$ from natural gas and the remainder from nuclear technology (International Renewable Energy Agency (IRENA), 2021).

\subsection{PERFORMANCE ASPECTS OF RENEWABLE ENERGY GENERATION}

Marion et al. (2005) stated that performance of a solar PV system may distinguish as per technology, design, and location. As per the findings of Khan and Arsalan (2015), the theory of photoelectric effect electrical energy can be obtained directly from solar energy by implying photovoltaic (PV) technology. Electricity is created by protons in the form of sun light striking a silicon semiconductor which causes electrons to flow. Sunlight is straight away converted into electrical energy where solar power generating systems take advantage of this property (Kyocera, 2016). This produced direct current (DC), which is converted into alternating current (AC) by a power inverter then moves through a circuit breaker to power the required unit.

The most frequently used materials in solar panels include mono and poly-crystalline silicon, Gallium arsenide (GaAs), Cadmium telluride (CdTe), while triple-junction solar cells are comprised of Indiumgallium phosphide (InGaP). A solar cell is usually a small scale electricity generation device. Several solar cells are assembled together to form a module of multiple cells in order to generate electricity at a larger scale where these modules are then connected into a photovoltaic (PV) array which length up to several meters (Khan and Arsalan, 2015). A grid-connected one fixed to the existing power grid, which supplies electricity to a facility for immediate use, or to a battery for storage are the types of PV systems available. As per the findings of Bandara, et al. (2020), PV-grid system is proven to be the most suitable solution for Sri Lankan context due to reduced cost of energy and environmental benefits. Further, the authors point out that off grid systems are the least suitable systems for Sri Lanka due to high cost of energy arising from the high purchase price of batteries.

The growing demand in energy has compelled the incorporation of renewable energy resources, such as solar and wind energy into the power grid (Boutoubat, Mokrani, and Machmoum, 2013). Owing to its capability to generate electricity up to megawatts, wind power can cater the electricity demand by supplying energy to the grid (Beddar, et al.,2016). Off-grid systems use batteries to store excess energy to provide a continuous supply of energy (Babazadeh, Hertem, and Nordstrom, 2016). Similarly modern wind turbines can produce AC power straightly with the improvement of technology (Lu, et al., 2015). Wind power is one of the most favourable GHG mitigation technologies with huge resource availability and a large deployment rate (Dai et al.,2015). Converting wind energy to electrical energy to generate power resembles to the mechanism of generating electrical energy by turbines from wind which are connected to the circuits to charge batteries and transmit power to large utility grids ( $\mathrm{Li}$ and $\mathrm{Li}, 2016$ ).

Wind turbines convert kinetic energy of wind to mechanical energy and finally to electrical energy, so the electricity energy is exploited from wind in tradition. Automating the entire electricity generation process of wind turbines, to get along with mechanical friction might be affected by any damages or shortcomings that might occur due to severe climate changes (Aquila et al., 2016). As per the ideas of Marimuthu and Kirubakaran (2014), In order to gain a maximum power extraction, the turbine should always face the wind direction.

\subsection{EMERGENCE OF HYBRID RENEWABLE ENERGY SYSTEMS}

The lack of consistency in renewable energy streams creates a non-reliability of energy generation (Rahman, et al., 2015). Energy security at majority of the time encourage renewable energy systems (Johansson, 2013), where implementation of hybrid energy systems is considered one of the most guaranteeing applications of technology of renewable energy (Nema and Nema, 2009). Aghapouramin (2020) investigated the applicability of wind turbine, PV panels, and diesel generator-based hybrid renewable energy system for six off-grid remote villages of East Azerbaijan province, Iran. Adan and Filik 
(2021) conducted a study to determine the technical and economic evaluation of a standalone and on grid hybrid system to supply power to the Department of Electrical and Electronics Engineering in Eskisehir Technical University, Turkey. Tiwari, et al. (2017) examined the possibilities of power generation through hybrid renewable energy systems in South Asian nations including Sri Lanka. Moreover, Rezaie, et al. (2011) determined that the hybrid technique is more desirable and can grant higher efficiency, lower energy cost and progress sustainability through lower emissions. Similarly, Ehyaei, et al. (2012) considered the economic, energy and emissions perspectives for an onsite hybrid system in a residential building and ascertained that a hybrid system can accomplish a first class performance. Moreover, in research carried out by Juserius and Ström (2021), the authors have identified that the optimal dimension of the hybrid renewable systems is profitable and will align with the Sri Lanka's goal of achieving $100 \%$ renewable energy by the year of 2050. Further, the authors highlight that the application of solar - wind hybrid renewable systems for households would be favourable in a sustainability perspective.

\section{Research Methodology}

An extensive literature review provides a basis for the researcher to establish a proper understanding on the research concept through congregation of available knowledge around the research area. Therefore, a comprehensive literature review was carried out on utilization of energy, renewable energy sources, performance aspects and hybrid renewable concept using numerous literature sources. A well-defined interview guideline was formed to gather the expert opinions on hybrid renewable energy systems using the findings of the literature survey. Since the research aim was to investigate the applicability of solarwind hybrid concept as a sustainable energy solution to the expected future energy deficit in Sri Lanka, information gathered were needed to be evaluated in a descriptive way based on a qualitative research approach. Data collection was carried out using an interview guideline through expert opinion surveys involving Eight (08) experts. Since the number of available experts on hybrids is minimal within Sri Lanka due to this concept still being a grooming concept, snow balling method was used in deciding the composition of interview participants in gathering details. Data analysis was conducted through manual content analysis, and the analysed data were validated through two (02) industry experts. The profile of experts contacted for the study is illustrated in Table 01.

\begin{tabular}{|l|l|l|l|l|}
\hline $\begin{array}{c}\text { Interview } \\
\text { Participant }\end{array}$ & \multicolumn{1}{|c|}{ Discipline } & $\begin{array}{c}\text { Experience } \\
\text { (Years) }\end{array}$ & \multicolumn{1}{c|}{$\begin{array}{c}\text { Awareness of } \\
\text { the hybrid } \\
\text { concept }\end{array}$} \\
\hline IP1 & $\begin{array}{l}\text { Former Director General/ Senior } \\
\text { Lecturer }\end{array}$ & 35 & Expert in field of solar, wind, biomass, and hybrid & Well aware \\
\hline IP2 & Director General & 20 & Expert in field of solar, wind and hybrid \\
\hline IP3 & Managing Director/ Visiting Lecturer & 30 & Expert in field of solar, wind and hybrid & Well aware \\
\hline IP4 & Training Engineer & 15 & Expert in field of solar and wind & Well aware \\
\hline IP5 & Senior Lecturer/ Consultant & 16 & $\begin{array}{l}\text { Expert in field of sustainable design and } \\
\text { construction }\end{array}$ & Aware \\
\hline IP6 & Senior Lecturer/ Consultant & 15 & Expert in field of solar & Aware \\
\hline IP7 & Senior Lecturer/Consultant & 16 & Expert in field of solar & Aware \\
\hline IP8 & Senior Lecturer/Consultant & 15 & $\begin{array}{l}\text { Expert in field of high voltage engineering, electric } \\
\text { power, wind }\end{array}$ & Aware \\
\hline
\end{tabular}

Table 1: Profile of interview participants

\section{Research Findings}

\subsection{CURRENT PRACTICES DURING INSTALLATION OF SOLAR PANELS}

Interview participants were asked to provide their opinions on the current practices during installation of solar panels in Sri Lanka and it was revealed that the roof top panels are the most popular option. Three (03) schemes mentioned by IP2 and IP8 were net metering, net accounting, and net plus, which are used in connecting the solar panels.

\subsubsection{Net Metering}

According to IP2, Net metering concept is where the electricity generated is taken to the Ceylon Electricity Board (CEB) and it is used to balance the monthly electricity bill. Here the produced excess energy can be saved for future, to be used on a higher consuming period just like saving in a bank. IP8 emphasized that most of Sri Lankans are using Net Metering system currently, which allows the net electricity costs to be reduced to zero, but no further. From 2016 September in Sri Lanka, the user can receive payment for any 
excess electricity that generated, in what is known as a Feed-In Tariff system. It was highlighted by IP2 that consumers with higher electricity consumption (6\% or $7 \%$ of Sri Lankans) came up with the concept of generating electricity by solar, due to the lesser cost per unit than the cost per unit given in the CEB tariff. However, the medium and low level consumers are still stagnant on adopting Net Metering system.

\subsubsection{Net Accounting}

IP2 highlighted that net accounting is the concept where if the solar panel of a specific user generate 200 units and if only 100 units were used, for the extra 100 units, Rs. 22 per unit will be paid for the first 7 years of installation and Rs. 15.50 per unit will be paid for the following 13 years. This is a concept applicable for 20 years after installation. IP8 confirmed the statement of IP2 explaining that if the generated units of electricity using the solar panels are greater than the amount consumed, the customer will be paid Rs.22.00 per unit during the first 07 years and from $8^{\text {th }}$ year onwards the consumer will be paid Rs. 15.50 per unit. If the consumption is greater than the generated amount, the consumer has to pay for the excess electricity consumed at the existing electricity tariff under this scheme.

\subsubsection{Net Plus}

IP2 explained that the net plus concept is where a certain solar panel generate 200 units, the whole 200 units will be exported to the CEB and a unit rate of Rs.22 per unit is paid. If the consumer consumes 100 units per month it is being charged according to the prevailing tariff method. This is useful for low-income people who use less than 100 units per month where 1 unit will cost around Rs.7.00. IP8 mentioned that net plus scheme is where the amount of electricity generated using the solar panels are being paid a fixed price by the CEB. Unlike net metering method there is no link between the electricity consumption of the customer and the electricity generation.

\subsection{UTILIZATION LEVEL OF SOLAR ENERGY IN SRI LANKA}

Seven (07) participants except IP6 agreed that solar energy is very popular among the Sri Lankans and the overall opinion was that promoting solar is an advantage to Sri Lanka. IP1 highlighted "Approximately 6500 solar systems have been installed around Sri Lanka, which produces 33 Mega Watts (MW) in total. 1500 systems are being proposed which will produce another $12 \mathrm{MW}$. The higher number of suppliers have improved the supply without any delay and shortage".

Further, IP1 stated that solar energy produced by plants basically cost about Rs.18 per unit for the consumer according to the tariff (without tax) and it takes Rs.16 cost per unit as the generation for the government. It was also highlighted that, in terms of personal level industries and high end consumers, a higher value is paid which is around Rs.30-40 per unit, where solar becomes a profit, if the usage per month is approximately higher than 200 units. Conversely, government will be losing high end consumers with the usage of solar panels has been a national financial concern. In contrast, IP4 stated that solar energy utilization is still at very low scale. IP7 further highlighted that the popularity of solar installation attracts lot of suppliers, but most knowledgeable people choose only solar instead of Solar PV and solar thermal, which are much effective applications. This nature demands the government to carry out more awareness programs to expand the market by educating the citizens.

\subsubsection{Government Efforts for Solar Energy Utilization}

All the participants agreed that full support from policy and institutional level has been granted by the government of Sri Lanka. IP2 explained that, with the drought season starting from February, it will be very useful if renewable electricity generation methods were implemented. Further, it was expressed that government has given effort to implement a $100 \mathrm{MW}$ (Megawatt) project in Siyambalanduwa and Monaragala areas. Licenses have been offered to implement projects totalling $70 \mathrm{MW}$ which are being planned to be implemented in Hambantota, Welikanda and Kilinochchi areas. In Punarin area 200MW of wind energy and 400MW of solar is being planned. IP3 mentioned that the future megapolis area will produce PV cells up to about 5-10GW (GigaWatt) by 2030. IP1 mentioned that a tax free import grant was offered to all the solar panels, inverters and other parts needed for installation which was regularized from December 2016. Moreover, IP3 emphasized that, Since CEB has offered net metering and net accounting for private suppliers and due to over production of panels, the cost of installation has been brought down. IP2 revealed that a project is now being implemented where CEB provides free solar panels to temples in Sri Lanka. This is mainly because CEB provides energy to temples at a very cheap rate, which is around Rs.3.50 per unit. Due to unit cost being around Rs.15, and specifically around Rs.18 per unit these days due 
to thermal electricity generation, CEB is enduring a huge loss which is about Rs. $12-15$ per unit. Therefore, when compared to the loss per unit it is more profitable to provide free solar panels to the temples.

\subsubsection{Research and Development on Solar Energy}

As mentioned by IP8, the National Engineering Research and Development (NERD) centre is involved in research activities on alternative and renewable energy technologies. Also, NERD has developed several renewable energy technologies associated with solar, wind and biomass to local conditions. IP1 further mentioned that Sri Lankan government is having more investment on research for solar installations. IP2 further stated that research and development has reduced the overall cost of solar panels during last few years and IP1 mentioned that the knowledge has been created among the society with the expertise of Research and Development (R\&D).

\subsection{CURRENT PRACTICES DURING INSTALLATION OF WIND TURBINES}

\subsubsection{Grid Connected}

IP1 highlighted that grid connected large scale is the successful method of turbine installation in Sri Lanka than off grid method. Currently grid connected large scale wind plants installed around Sri Lanka, produces approximately $129 \mathrm{MW}$ in total where a majority of contribution is given from Puttalam and Kankasanthurai plants. Another $100 \mathrm{MW}$ project is being installed at Mannar which is funded by Asian Development bank. A 20MW project has been proposed recently. Currently, the private sector is handling the projects with 10MW capacity.

\subsubsection{Off Grid}

IP1, IP2, IP3, IP4 and IP8 affirmed that off grid wind turbines will not be successful in Sri Lanka. IP2 and IP8 mentioned that wind turbines on separate buildings are not available within Sri Lanka according to their knowledge. IP1 confirmed the negative opinion on off grid wind turbine by stating that, a trial was conducted in Colombo and that was not successful. But in contrast IP3 stated that if off grid wind turbines can be installed in industrial buildings such as tea, a considerable amount of savings can be made. Further IP1 mentioned that, approximately 30-40 turbines fixed off grid are currently not operational due to CEB grid development to those off grid areas, and due to the higher maintenance cost of off grid wind energy generation. But local developments have been taken place for the installation and running of off grid wind turbines, where the supply was given to nearly 15-20 dwellings.

\subsection{UTILIZATION LEVEL OF WIND ENERGY IN SRI LANKA}

The existing level of wind energy utilization was reviewed through interview respondents. IP5 and IP7 specifically stated that still very limited installations have been taken place. IP3 highlighted that, Sri Lanka has not hunted for the best wind generators available worldwide.IP2 mentioned that Sri Lanka is currently using grid connected method where $129 \mathrm{MW}$ capacity is produced. IP1 reinforced that statement by stating that the majority of contribution is given from Puttalam and Kankasanthurai plants. For an example, in Kalpitiya $10 \mathrm{MW}$ project has 5 towers with $2 \mathrm{MW}$ capacity. Turbulence is higher in central province. But in Puttalam, Punarine, Mannar, Jaffna regions a steady wind flow is available. The area above Puttlam is declared as a good region for wind within the world due to being an open area in Sri Lanka with no disturbance and higher wind flow. IP2 further mentioned that a supply of onsite blade builders and other wind developers are now available in Sri Lanka. $150 \mathrm{~kW}$ capacity 6 wind turbines are available at Balangoda. Blades of wind turbines have been built and destructive tests have been performed within the site, but it has been deduced that importing from mass scale producers in India is still cheaper than building locally.

\subsubsection{Government Efforts for Wind Energy Utilization}

As elaborated by IP1, Wind resource map shows that wind is a recessive case to certain areas of Sri Lanka. IP1 further explained that resource mapping has been done by the SLSEA where higher potentials have been identified. As per IP1, Central province has the highest potential and technical viability, but due to the turbulence issue it's not viable economically. Jaffna Lagoon has a 4000MW capacity while Mannar region has a capacity of $400 \mathrm{MW}$. IP2 mentioned that 200MW of wind energy is being planned in Punarine area. As $100 \mathrm{MW}$ project is being implemented in Mannar, the remaining 300MW could be given to the private sector for installations. This is known as "Standard power purchase agreement". SLSEA's role is to approve 
the projects according to the relevant procedures. Usually, the procedure was to give chance according to first come first out basis, but currently the competitive bidding method is being utilized.IP1 stated that wind energy generated in a good potential site at Jaffna basically costs around Rs.12 per unit which is lower than solar per unit generation cost. The tariff was Rs.18 per unit. Therefore, the tariff was lowered with the bidding process. There are technologies with cost effective feed in tariff model, which considers the cost for solar wind biomass technologies to declare the suitable tariff. CEB signs the agreement considering this feed in tariff method, but resources allocated are provided by SLSEA. IP2 further mentioned that a separate renewable energy ministry is being incorporated in coordinating further matters on renewable energy. IP1 mentioned that, with the location change the cost per unit might differ. It is a well-known fact that in the earlier days small scale windmills were present with battery charging which had $100 \mathrm{~W}, 250 \mathrm{~W}$ to $1 \mathrm{~kW}$ capacities. The cost per unit was about Rs.35 at those times.

\subsection{HYBRID RENEWABLE ENERGY SYSTEMS}

As a possible solution to the problems such as seasonal variations and fluctuations, high cost, lack of storage and unreliability associated with the reliance on a single renewable energy source, hybrid renewable energy systems have been emerged. According to IP4, IP7 and IP8 use of renewables would save non renewables in addressing the expected future energy deficit. IP2 further stated that, there will be a time where it is not possible to produce energy through non-renewable resources. Therefore, definitely renewables will be the final option and hybrid approach will be the only alternative left. IP3 reinforced IP2's statement mentioning that, hybrid system would be the only solution to curtail rising energy prices. IP5 had a controversial opinion that world energy demand will not be able to be satisfied only by renewables, and nuclear power and other energy sources will be invented. All the participants agreed that the final intention of a hybrid system is to address the expected future energy deficit. Six (06) participants confirmed that reliability can be achieved through a hybrid system and IP1 specifically mentioned that there is more flexibility to choose between any renewable source and in any percentage mix to gain a better design. Three (03) participants mentioned that energy efficiency is an advantage of a hybrid system. According to IP1, it's not compulsory for a hybrid system to increase system efficiency, but the aim of having a hybrid is to make the system efficient and optimized. IP2 further mentioned that hybrid renewable system is a complex theory where number of renewable resources are being used, which in return smoothens the result. IP1 mentioned that something which cannot be done through a single renewable energy source will be done by a hybrid in order to tackle energy issues. Therefore, in long term aspects, hybrids should not be installed specifically for one single place, but when it in connected to feed the grid, the supply will be island wide. Four (04) participants mentioned that due to the less impact on the environment and environment friendly energy supply, hybrid renewable systems assist to reduce global warming and climatic change issues. IP1 added another importance of hybrid renewable systems as space planning which is possible when combining of renewable resources.

\subsection{HYBRID RENEWABLE ENERGY SYSTEM APPLICABILITY IN SRI LANKA}

There are several reasons for overlooking on the possibilities of applying hybrid renewable systems in Sri Lankan Context. IP7 stated that Sri Lanka is a not up to date in terms of the latest technology. According to IP2, Lower funding or capital investments is the major reason where the hybrid area is not studied deeply even though the potential is present. IP1 mentioned that Sri Lankans are not used to appreciate clean and green energy and general public always concerns on the low cost. Further, it was mentioned that in countries like Germany, people are willing to even pay more when it comes to green energy such as bio diesel. According to IP6, due to grid network being imbalanced in Sri Lanka, energy balancing is facing problems which in return make it difficult to provide a backup storage to hybrid systems. According to IP1, IP2 and IP8, Pattiyapola, the world's first 100\% renewable energy driven village with solar, wind and biomass combinations, is the only hybrid renewable project in Sri Lanka. As stated by IP1, due to the more human labour involvement for biogas generation, like having cow dung collected, people started refusing those sources with the introduction of CEB grid connectivity, leading to project failure. However, All the participants agreed that hybrid approach will have significant contribution to the renewable energy usage in Sri Lanka. IP1, IP2 and IP8 specifically stated that for hybrid renewable energy systems to have a significant contribution, it should be grid connected and supplied to the system. IP8 mentioned that if solar-wind hybrid approach is finally established in Sri Lanka ultimate saving of $20 \%$ from the total energy supply of the country can be achieved through solar and wind energy resources. IP1 mentioned that, if hybrid systems were further broadened for thermal, electricity and transport sectors and combined together to make green cities, regions, provincial councils, and if modelling and circular economic approaches are applied, that will be the best option for Sri Lanka. As explained by IP1, compared to other renewable sources like biomass, the operation of solar and wind has a less involvement of people. IP3 
stated that specialty of solar and wind is being abundant and unlimited and there is no cost incurred in obtaining those resources compared to other renewables such as biomass and hydro. IP3 further emphasized that, although biomass is also taken as a renewable, it will take decades of years for trees to grow, and hydro power will also face troubles in the near future with limited rain. As per IP2 and IP8, only about $4 \%$ of the energy supply is covered from solar and wind and it can be extended up to about $20 \%$. In developed countries solar and wind coverage is about $35 \%-40 \%$ of the supply. According to IP7 and IP8 solar and wind have a good future due to being clean energy sources.

Seven (07) participants suggested that grid connected areas with abundant supply of solar wind will be the best situation to apply the solar wind hybrid approach, where a sustainable energy solution can be provided when it is connected to feed the grid where the supply will be island wide. Areas such as Jaffna, Punarine, Mannar, Puttlam and Hambantota were suggested by IP1, IP2 and IP8. IP1 further highlighted that, the only problem in solar and wind together is the resource availability in the same place. IP2 stated that, solar and wind concentrated areas like Punarine and Kilinochchi should produce their maximum capacities and distribute it among industrial zones like Katunayaka, Biyagama and Awissawella. For this, the system should supply to the grid in order to distribute. Therefore, Colombo can use energy generated by solar and wind in Jaffna area for their consumption. IP2 further emphasized that, for 5-10 years in the future, feeding to the system will be the best option. This is because the design efficiency will decide upon the load pattern. With the operation pattern in Sri Lanka feeding to the grid will be an investment to the particular company. Therefore, connecting to the grid was the most recommended approach because connecting to the grid will not generate any disadvantage as it can be switched off or on when the renewable resource supply is higher and lower, respectively. It is impossible to $100 \%$ rely on renewable energy, as there are times with no solar or wind production. Battery supply will also give the supply for another 24 hours which is a temporary solution. Therefore, if electricity is generated through a hybrid system, and if the grid is present in that area, it is best to get connected to the grid and feed the grid. IP4 and IP1 stated that apart from grid connected areas with abundant supply, off grid areas where electricity generation is not provided through grid also can use this approach. CEB has already handled projects which are Korean funded with hybrid systems of solar, wind and diesel for islands named Eluvativu, Nainativu, Analathivu and Pungudutivu where about 300-400 people live and where the minimum grid connectivity is not cost effective. However, due to the unreliability of solar and wind energy resources, IP2 stated that the system should be provided with a diesel generator/backup storage or some other stand by source if it is not connected to the grid. According to IP2, in terms of buildings, hybrid concept is still in the level of research and development. For a building, a standby system should be there for an efficient hybrid supply. Potential and environment is present for hybrids in Sri Lanka, and it should be supported with a standby power system. For separate buildings, a study should be done in order to finalize whether a hybrid is suitable and what renewable resources in what percentage should be used. If the hybrid is for separate buildings different types of industries were suggested by the experts in order to implement the hybrid system. Out of eight (08) participants seven (07) agreed that tea industry is the best possible industry to implement hybrid solar wind system. The major reasons were the higher roof top areas of tea factories, which can be used for roof top solar panels and tea factories being situated in higher altitudes where wind can be grasped easily.

\subsection{NATIONAL LEVEL CONTRIBUTION TO ENHANCE THE HYBRID SYSTEM}

Policies and regulations for the betterment of energy saving strategies was the most highlighted suggestion in terms of national contribution which was discussed by four experts. IP4 and IP8 further stated that awareness programs should be held in order to make people aware about the loan facilities available and the importance of sustainability. Three (03) participants stated that soft loans should be introduced to people and tax concessions should be provided. In terms of investments, as per IP1 national level funding and grants should be acquired for investments on renewable energy. IP7 stated that if higher investments can be done high technology can be used in producing green energy. IP3 stated that funding for research has to be in place for the development of renewable energy. And IP5 also stated that research and studies should be done to determine the best hybrid system and optimum mix. IP3 stated that, "What is missing is the policy makers' updated thinking and investment in research".

Strengthening of the grid and providing backup storage goes together. IP1 stated that national level discussions should be held in terms of the increasing of backup storage of grid. IP2 highlighted that, there are number of projects going on related to renewables and hybrids. However, the problem is in the CEB grid. Reliability of the grid should support the fluctuating demand, where no failure should happen when a sudden fall in energy generation happens like in the failure of Norochchole. The drop should be gradual not sudden when one station fails to supply. If not, the whole system will trip due to sudden fall. The grid should be made stronger. For example, switch gears and control system should be improved to reduce the 
damage to the total grid". IP7 stated a different opinion by mentioning that, "If electricity price per unit is further increased and if loans are offered to people for solar installments, most will move to solar PV".

\subsection{FRAMEWORK TO IMPLEMENT HYBRID SOLAR WIND ENERGY GENERATION APPROACH IN SRI LANKA}

Interview participants were asked to give their opinions about the main steps which should be identified in designing the framework to implement hybrid solar-wind energy generation approach for a specific location. After analysing the expert opinions, six (06) main steps: i) Demand assessment, ii) Resource assessment, iii) Storage Assessment, iv) Modelling and feasibility study, v) Implementing of optimized design and vi) Operation and controlling were identified which are discussed below in detail.

I) Demand Assessment- Minimizing total electricity consumption was highlighted by all the interviews as the pertinent factor. As stated by IP2, the location, daily/weekly electricity demand and consumption patterns were identified as critical factors in calculating the total electricity consumption.

II) Resources Assessment - The interview participants mentioned that optimizing total electricity supply is important. According to IP2 and IP4, the amount of energy generated by solar, and wind should be calculated separately.

III) Storage Assessment- Selecting the most appropriate storage method to fill the energy gap was identified as important by the participants. Further, the gap between the minimized electricity consumption and optimized electricity supply should be quantified.

IV) Modelling and feasibility study- As stated by IP2 and IP4, the electricity consumption patterns and supply patterns were identified as major factors to be considered during modelling to gain feasible combinations of solar and wind energy supply, which can fulfill the determined energy demand.

V) Implementation of the optimized design- Majority of participants stated that after modelling and the feasibility study, the next step is selecting the optimized feasible combination among the combinations. As emphasized by IP1 and IP2, investment available and the return on investment were identified as the major factors to be considered in this stage.

VI) Operation and controlling- As the final stage operating and controlling of the implemented hybrid design was identified by the interview participants. Identifying the specific intervals in which the controlling should be done was identified as an important aspect (IP1 and IP2), in order to adopt the hybrid system more efficiently to the installed location.

Few qualitative questions were asked from the experts in terms of the content, clarity, and data presentation of the proposed framework. The two experts validated the findings and the final approach used in the framework after some minor adjustments. The finalized approach is illustrated in Figure 2.

\section{Discussion}

Hybrid renewable system is a novel concept which combines multiple energy sources to provide an uninterruptable energy flow to different applications. Therefore, this paper aims to explore the applicability of hybrid renewable energy generation approach in Sri Lanka. The findings revealed that rooftop solar panels are the most popular option in Sri Lankan context. Net metering system is a popular option among high scale electricity consumers in Sri Lanka where the solar energy generated could be used to balance the electricity bill. Net accounting is another solar tariff system implemented by CEB to pay the consumer based on energy generation. Further, the respondents introduced another system known as Net plus, which is beneficial for low income consumers. The respondents highlighted the fact that even though solar is a popular concept in Sri Lanka, most of the consumers use solar only instead of effective applications such as solar PV and solar thermal. This indicates that there is a gap in consumer awareness regarding solar applications. Further, the respondents explained that the government is having different initiatives and R\&D programs to promote solar energy in Sri Lanka. 


\section{HYBRID SOLAR- WIND RENEWABLE ENERGY GENERATION APPROACH}

\footnotetext{
"A Framework Which Focuses on Promoting Hybrid Solar-Wind Renewable Energy Generation Approach in Sri Lanka as a Clean Sustainable Energy Solution"
}

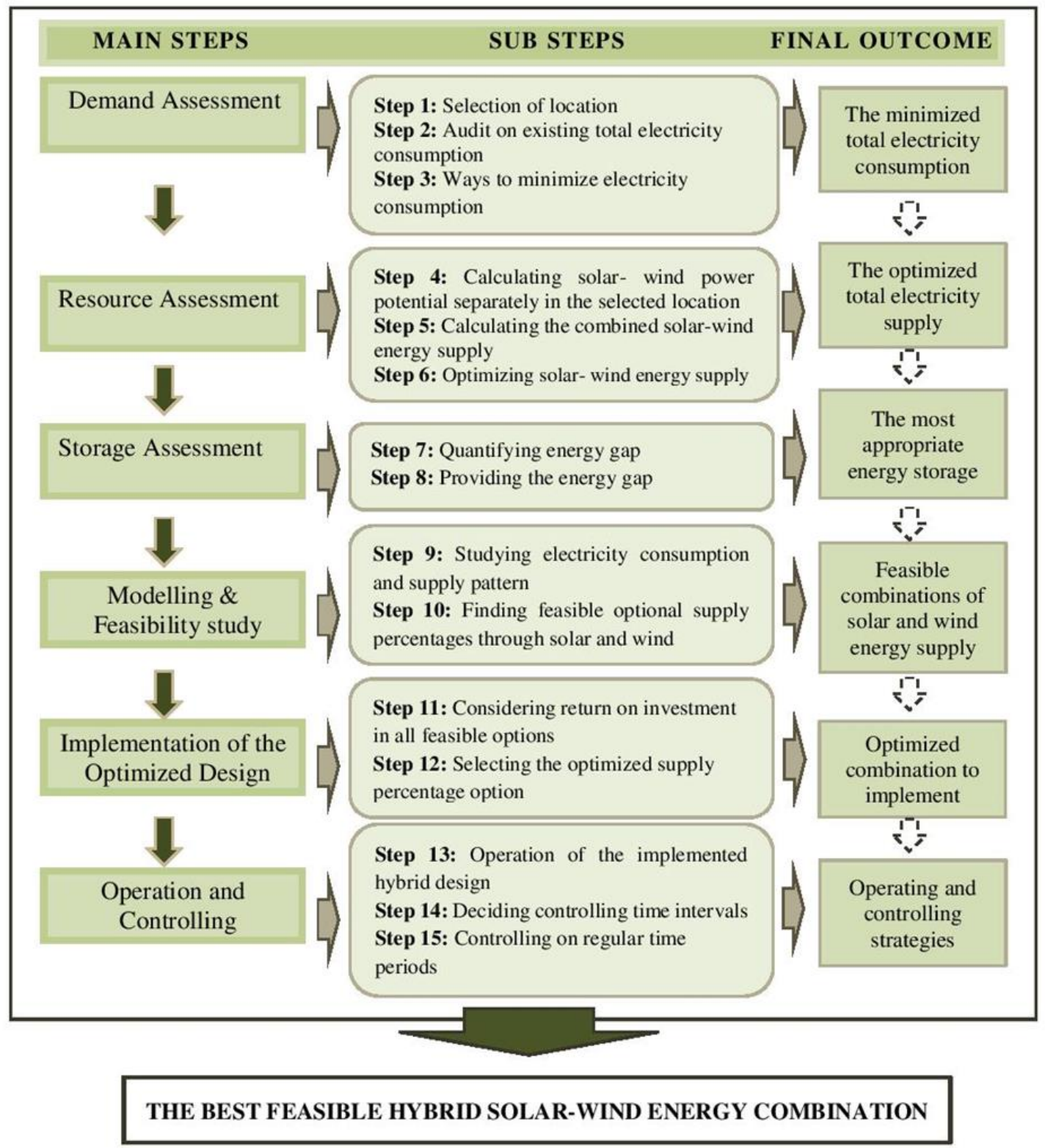

Figure 2, Proposed framework to implement hybrid solar-wind energy generation approach for Sri Lanka

In relation to Sri Lankan context, the respondents affirm that grid connected system will be more suitable to implement wind energy. Moreover, the findings reveal that off grid systems would not be much suitable due to the high capital cost and operational difficulties as explained in the literature sources (Bandara, et al., 2020). Similar to solar, the government has positive initiatives to promote wind energy in Sri Lanka such as resource allocations, investments, and partnerships with private sector. The respondents highlighted the benefits of hybrid renewable energy systems as saving non renewables in addressing the expected future energy deficit, being the only solution to curtail rising energy prices, reliability in energy supply, energy efficiency, reducing global warming and climatic change issues and space planning. Despite having issues such as absence of updated technology, lack of funding or capital investments, lack of appreciation in clean and green energy by consumers and difficulty to provide a backup storage to hybrid systems, experts agree that solar wind hybrid renewable system is a feasible application to mitigate the energy crisis faced by Sri Lanka. The experts stated that, when compared with other renewable sources such as biomass and hydropower, solar and wind has distinctive benefits such as abundance in supply, lack of labour intensivity and being clean energy sources. Moreover, as previously stated in literature, the 
research findings emphasize that grid connection is the most suitable method for Sri Lankan hybrid renewable applications as it enables a reliable and island wide supply. The off grid systems should be supplemented with a backup energy source to ensure the reliability of energy supply. Further, as explained by respondents, tea industry is the most suitable industry to implement solar-wind hybrid systems due to vast roof span in factories and abundance of wind due to high altitude. Through strategies such as provision of tax concessions, soft loans, research funding and awareness sessions the hybrid renewable concept could be strengthened in Sri Lanka. Based on the research findings, a framework was designed to successfully implement solar-wind energy generation approach in Sri Lanka.

\section{Conclusion and the way forward}

With the worldwide energy challenge and attention towards sustainability and green energy solutions, renewable energy usage plays a major role in the immense process of sustaining energy. Sri Lanka being a country which has less interest towards human involvement in operations, solar and wind can be stated as the best practical renewable solution due to abundance, non-labour intensivity and clean supply etc. The study sought to explore the applicability of hybrid renewable energy generation approach in Sri Lanka. The literature provided insights into energy utilization among different sectors, performance aspects of renewable energy and hybrid concepts. Followed by the comprehensive literature review, the research initially identified the existing systems of connecting solar (net metering, net accounting and net plus) and wind (grid connected and off grid) energy sources and explored the possibilities of the hybrid system in Sri Lanka. Further the benefits and issues of hybrid systems were outlined through the findings. The experts collectively recommended solar-wind hybrid renewable system as a suitable application for Sri Lanka. Finally, a validated model was created which outlined the implementation stages of hybrid renewable concept. The proposed framework can be used as a guide by the government, policy makers and relevant authorities to promote hybrid solar-wind energy generation approach in Sri Lanka. It is recommended to consider the tea plantation sector as a potential sector to implement the hybrid solarwind energy generation approach. Further, it is recommended to broaden the hybrid concept with the circular economic applications by interconnecting the hybrid concept in electricity, thermal and transport sectors.

\section{References}

Aghapouramin, K. (2020). Technical, Economical, and Environmental Feasibility of Hybrid Renewable Electrification Systems for off-Grid Remote Rural Electrification Areas for East Azerbaijan Province, Iran. Technology and Economics of Smart Grids and Sustainable Energy, 5(20), 1-20.

Alrikabi, N. (2014). Renewable Energy Types. Journal of Clean Energy Technologies, 61-64.

Aquila, G., Rocha, L., Rotela Junior, P., Pamplona, E., Queiroz, A., \& Paiva, A. (2016), Wind power generation: An impact analysis of incentive strategies for cleaner energy provision in Brazil. Journal of Cleaner Production, 137, 1100-1108.

Babazadeh, D., Van Hertem, D., \& Nordström, L. (2016). Study of centralized and distributed coordination of power injection in multi-TSO HVDC grid with large off-shore wind integration. Electric Power Systems Research, 136, 281-288.

Bandara, A., Hemapala, K. \& Herath, A. (2020). Optimal sizing and economic evaluation of a photovoltaic integrated energy system - A case study for a semi-urban area in Sri Lanka in ICRAIE 2020, Jaipur. India; IEEE.

Beddar, A., Bouzekri, H., Babes, B., \& Afghoul, H. (2016). Experimental enhancement of fuzzy fractional order PI+I controller of grid connected variable speed wind energy conversion system. Energy Conversion and Management, 123, 569-580.

Boutoubat, M., Mokrani, L.\& Machmoum, M. (2013). Control of a wind energy conversion system equipped by a DFIG for active power generation and power quality improvement. Renewable Energy, 50, 378-386.

Bull, S. (2001). Renewable energy today and tomorrow, Proceedings of the IEEE, 89 (8), 1216-1226, IEEE. Converting Sunlight into Electricity | Solar Power by Kyocera | Solar Power Expo | Kyocera. (2016).

Dai, H., Silva Herran, D., Fujimori, S., \& Masui, T. (2016).Key factors affecting long-term penetration of global onshore wind energy integrating top-down and bottom-up approaches. Renewable Energy, 85, 19-30.

Daim, T., Harell, G., \& Hogaboam, L. (2012). Forecasting renewable energy production in the US. Foresight, 14(3), 225-228.

Ehyaei, M., Ahmadi, P., Atabi, F., Heibati, M. \& Khorshidvand, M. (2012). Feasibility study of applying internal combustion engines in residential buildings by exergy, economic and environmental analysis. Energy And Buildings, 55, 405-413.

Energy Information Administration, (2016), International Energy Outlook 2016.

International Energy Agency (IEA), (2020), Key World Energy Statistics.

International Renewable Energy Agency (IRNEA), (2021), World Energy Transitions Outlook. 
Jacobson, M. Z. \& and Delucchi, M. A. (2011). Providing all global energy with wind, water, and solar power, Part I: Technologies, energy resources, quantities and areas of infrastructure, and materials. Energy Policy, 39(3), 1154-1169.

Johansson, B. (2013). Security aspects of future renewable energy systems-A short overview. Energy, 61, 598-605. Juserius, E. \& Ström, F. (2021). The potential of a Solar and Wind Hybrid system in Sri Lanka (Dissertation), DiVA.

Khan, J. \& Arsalan, M. (2016), Solar power technologies for sustainable electricity generation - A review , Renewable And Sustainable Energy Reviews, 55, 414-425.

Kolhe, M. L., Ranaweera, K. I. U. \& Gunawardana, A. S., 2015. Techno-economic sizing of off-grid hybrid renewable energy system for rural electrification in Sri Lanka. Sustainable Energy Technologies and Assessments, Volume 11, pp. 53-64.

Li, Y. and Li, Q. (2016), “Wind-induced response based optimal design of irregular shaped tall buildings. Journal Of Wind Engineering and Industrial Aerodynamics, Vol.155, pp.197-207.

Li, D., Pan, W., and Lam, J. (2014). A comparison of global bioclimates in the 20th and 21st centuries and building energy consumption implications. Building And Environment, 75, 236-249.

Marimuthu, C. and Kirubakaran, V. (2013). Carbon pay back period for solar and wind energy project installed in India: A critical review. Renewable And Sustainable Energy Reviews, 23, 80-90.

Marion, B., Adelstein, J., Boyle, K., Hayden, H., Hammond, B., and Fletcher, T. et al. (2005). Performance parameters for grid-connected PV systems in Photovoltaic Specialists Conference, 1601-1606.

Murshed, M., Kashif, A. \& Rashid, S., 2020. Modelling renewable energy adoption across south Asian Economies: Empirical evidence from Bangladesh, India, Pakistan and Sri Lanka. International Journal of Finance and Economics, 26(4), 1-26.

Nema, P., Nema, R., \& Rangnekar, S. (2009). A current and future state of art development of hybrid energy system using wind and PV-solar: A review. Renewable And Sustainable Energy Reviews, 13 (8), 2096-2103.

Rahman, M., Khan, M., Ullah, M., Zhang, X., \& Kumar, A. (2016), A hybrid renewable energy system for a North American off-grid community. Energy, 97, 151-160.

Rehman, S., Mahbub Alam, M., Meyer, J., \& Al-Hadhrami, L. (2012). Feasibility study of a wind-pv-diesel hybrid power system for a village. Renewable Energy, 38 (1), 258-268.

Renewables (2015), Renewable Energy Policy Network for the 21st Century- Global Status Report.

Rezaie, B., Esmailzadeh, E., \& Dincer, I. (2011), Renewable energy options for buildings: Case studies. Energy And Buildings, 43(1), 56-65.

Sawhney, A. (2021). Striving towards a circular economy: climate policy and renewable energy in India. Clean Technologies and Environmental Policy, 491-499.

Scheffran, J., Felkers, M. \& Froese, R. (2020). Economic growth and the global energy demand In: Green Energy to Sustainability, pp.1-44.

Sri Lanka Sustainable Energy Authority, (2018). Sri Lanka Energy Balance 2018.

Tiwari, et al. (2017). A Review on Microgrid Based on Hybrid Renewable Energy Sources in South-Asian Perspective. Technology and Economics of Smart Grids and Sustainable Energy, 2, 1-16.

Wang, X., Palazoglu, A. \& El-Farra, N. (2015), Operational optimization and demand response of hybrid renewable energy systems, Applied Energy, 143, pp.324-335.

Umayangani, A. (2019). Renewable Energy in Sri Lanka (Dissertation), DiVA.

Adan, H. K. \& Filik, Ü. B. (2021). Technical and economic evaluation of a standalone and on grid hybrid renewable energy: A case study at Eskişehir Technical University. Sigma Journal of Engineering and Natural Sciences, 39(2), 184-194.

Wijayatunga, P. (2014), Regulation for renewable energy development: Lessons from Sri Lanka experience. Renewable Energy, 61, 29-32. 